\title{
Different faces of a febrile state
}

\author{
Ewa Rymarz, Sylwia Milaniuk, Andrzej Prystupa*, Jerzy Mosiewicz
}

Chair and Department of Internal Diseases, University Hospital no.1 in Lublin, 16 Staszica Str., 20-091 Lublin, Poland

\begin{tabular}{ll}
\hline ARTICLE INFO & ABSTRACT \\
\cline { 1 - 2 } $\begin{array}{l}\text { Received 13 June 2014 } \\
\text { Accepted 14 July 2014 }\end{array}$ & $\begin{array}{l}\text { Fever develops in various diseases. It is mainly associated with infectious diseases but can } \\
\text { also occur in non-infectious ailments. Clinical symptoms are not always explicit, which } \\
\text { can hinder the diagnosis and delay the institution of appropriate treatment. The aim of } \\
\text { KEYWORDS: } \\
\begin{array}{l}\text { febrile state, } \\
\text { thlenic abscess. }\end{array}\end{array}$ \\
\begin{tabular}{l} 
splenic abscess. \\
\hline
\end{tabular}
\end{tabular}

\section{INTRODUCTION}

Determination of the cause of a febrile state is a difficult and often complex diagnostic problem due to aetiological diversity of elevated body temperature [2,3], defined as a morning body temperature above $37.2^{\circ} \mathrm{C}$ and an afternoon one above $37.7^{\circ} \mathrm{C}$. Generally, the body temperature above $37.2^{\circ} \mathrm{C}$ is considered the febrile state. [3]. The most common causes of elevated body temperature are infections caused by viruses (HIV included) and bacteria, followed by fungal infections. The other causes of febrile states include autoimmune diseases, collagenoses, in particular, neoplasms, diseases of the brain and cerebrospinal meninges, allergies, less commonly zoonoses and others $[6,7,8]$. Despite the advances in medical diagnostics, there is still a certain group of patients with fever, the cause of which remains unexplained [10].

We present a case of a patient with the febrile state of several-week duration and atypical disease manifestations, which required multi-directional diagnostic procedures and interdisciplinary management to be finally successfully diagnosed and treated.

\section{CASE REPORT:}

A 72-year-old patient was admitted to the Department of Internal Diseases due to the persistent several-week febrile state accompanied by extremely severe pain of the right lower limb. Prior to admission, the patient had been treated for arterial hypertension by the GP and neurologist. The following agents were prescribed: hypotensive drugs from the group of angiotensin-converting enzyme inhibitors, betablocker, indapamide and acetylsalicylic acid preparation.

\footnotetext{
Corresponding author

e-mail: andrzej.prystupa@umlub.pl
}

Arterial blood pressure was satisfactorily controlled. Based on the recommendations of the attending physicians, the patient had chest and hip joint X-rays, which did not demonstrate any abnormalities. On an outpatient basis, the patient received cefuroxime, diclofenac and dexamethasone without any therapeutic effect. On admission to the Department of Internal Diseases, the general condition of the patient was severe. He suffered badly and complained of persistent pain of the lower limb; his body temperature was $39^{\circ} \mathrm{C}$. The nutritional condition of the patient was normal (BMI: $28.6 \mathrm{~kg} / \mathrm{m}^{2}$ ). The physical examination of the chest and abdomen revealed no abnormalities, except for slight enlargement of the spleen. On palpation, accessible lymph nodes were not enlarged. Laboratory tests disclosed substantially elevated inflammatory indices CRP - $375 \mathrm{mg} / \mathrm{l}$ (range of $0-5 \mathrm{mg} / \mathrm{l}$ ), leucocytosis -22 thousand $/ \mathrm{mm}^{3}$, platelet count $-655 \mathrm{G} / 1$, increased levels of fibrinogen $-8.6 \mathrm{~g} / \mathrm{l}$ (reference values 1.8-3.5 g/l) and of D-Dimer - $7928 \mathrm{ng} /$ $\mathrm{ml}$ (norm above $500 \mathrm{ng} / \mathrm{ml}$ ) and $13397 \mathrm{ng} / \mathrm{ml}$ on the next determination. Moreover, hepatic enzymes, ALAT and AsPAT, were elevated, 92 IU/1 and 87 IU/1, respectively. The other laboratory results were within normal limits. Blood cultures were negative. Echocardiography did not show valve vegetation. Due to persisting severe pains in the right lower limb, the case was consulted with the vascular surgeon and the patient underwent the ultrasound of the lower limb venous system, which did not demonstrate venous thrombosis. MRI of the lumbosacral spine revealed only advanced degenerative-productive lesions. Abdominal ultrasound showed a slight enlargement of the spleen; $\mathrm{CT}$ of the abdomen visualised an irregular hypotensive lesion, $60 \times 50 \times 70 \mathrm{~mm}$, within the spleen [Fig. 1]. The nature of the lesion was suggestive of a subcapsular splenic haematoma. After the consultation with the surgeon, the patient was qualified for surgery during which the splenic abscess was found. Splenectomy was performed and febrile states as well as pain subsided. 


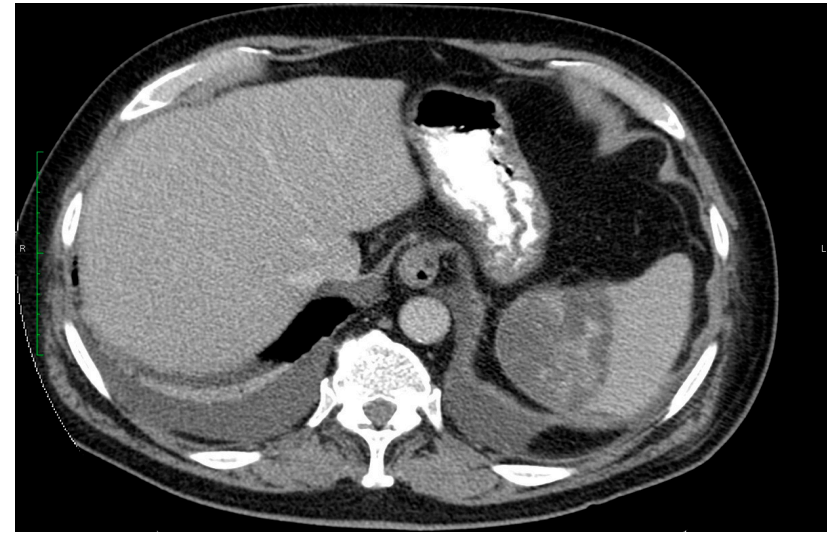

Figure 1. Abdominal CT scan showing a splenic abscess

\section{DISCUSSION}

Fever is the basic mechanism of the body response to infection. Moreover, it can play an important protective role $[11,4]$. The pathogenesis of fever is complex. The major role in its development is played by proinflammatory cytokines, particularly interleukin 1 and 6 (IL-1 and IL-6) and tumour necrosis factor alpha (TNF-alpha) [5]. Thus, elevated body temperature can be caused by any disease inducing the release of proinflammatory cytokines [12], mostly infections yet various non-infectious diseases, e.g. collagenoses and neoplasms, can also be involved [9,1]. Table 1 lists the most common non-infectious causes of fever.

Table 1. The most common non-infectious causes of fever

\begin{tabular}{|l|}
\hline - neoplasms, \\
\hline - collagenosis, \\
\hline - thrombophlebitis \\
\hline - deep vein thrombosis, \\
\hline - pulmonary embolism, \\
\hline - cerebral diseases (haemorrhagic and ischaemic stroke), \\
\hline - myocardial infarction, \\
\hline - pancreatitis, \\
\hline - cirrhosis of the liver, \\
\hline - haemorrhage from the gastrointestinal tract, \\
\hline - ARDS, \\
\hline - drugs (neuroleptics, steroid hormones) \\
\hline
\end{tabular}

Our case describes the diagnostic difficulties in determining the causes of the long-term febrile state. The difficulties were associated with the fact that the essential clinical symptoms were lower limb pains suggestive of venous thrombosis and a neoplastic spine lesion. Once CT of the abdomen was performed, further diagnostic management was continued in the right direction. Splenectomy with splenic abscess removal led to complete recovery of the patient. The postoperative management involved only several-week antithrombotic therapy. The case described evidences that not all febrile states can be treated on an outpatient basis and some cases require hospitalization in the department of internal diseases. Moreover, the diagnostic management should be based on the dynamics of clinical symptoms rather than the symptoms themselves. Accurate history taking can also be valuable. In our case, the patient remembered the injury to the abdomen sustained several months earlier, which was the likely cause of a haematoma followed by a splenic abscess. It seems that antibiotics and antipyretics used too hastily in such conditions decrease transiently the temperature, which may obscure the picture of disease and hinder the diagnosis. In many cases, the treatment with various antibiotics is initiated under pressure of patients and their families. Antibiotic management should not be a substitute for diagnosis. Considering the case presented, it is worth remembering that not all the abscesses within the abdominal cavity develop in a classical way; in some cases, such abscesses can imitate some other, completely surprising diseases, for example abscesses of splenic. In recent years abscesses of spleen have been more frequently observed. This is a result of immunosupresive treatment and more accurate diagnostic techniques.

\section{REFERENCES:}

1. Arslan F. et al: Splenic abscess caused by MRSA developing in an infarcted area: case report and literature review. J. Infect. Chemother., 851-4, 17(6), 2011.

2. Brncic N., Mijandrusic-Sincik B., Peric R.: Splenic haematoma as a first of manifestation cytomegalovirus infection. Coll. Antropol., 267-9, 34(2), 2010.

3. Chakarian J.C., Heron F., Belizna C.: Spontaneous splenic hematoma: trauma injury or drug reaction or both. Presse. Med., 1717-8, 34(22), 2005.

4. Halkic N. et al: Spontaneous splenic haematoma in a teenager with infectious mononucleosis. Chir. Ital., 929-30, 55(6), 2003.

5. Handler M.Z. et al: Fusobacterium necrophorum causing infective endocarditis and liver and splenic abscesses. Rev. Inst. Med. Trop. Sao. Paulo., 169-72, 53(3), 2011.

6. Hatzmichael E., Banetatos L., Stebbing J.: Sponateous splenic haematoma in a multiple myeloma patient receiving pegfilgrastim support. Clin. Lab. Haematol., 416-8, 28(6), 2006.

7. Hesstvedt L., Wilhelmsen M., Mengshoel A.T.: Two Norwegian patients with melioidosis presenting with bacteraemia and splenic and prostatic abscesses. J. Travel. Med., 418-21, 18(6), 2011.

8. Kundu P.R. et al: Isolated tuberculosus splenic abscess in immunocompetent individual. Asian. Pac. J. Trop. Med., 81-2, 4(1), 2011.

9. Lewis L. et al: Neonate subcapsular splenic haematoma. Indian. J. Pediatr., 950-2, 75(9), 2008.

10. Lewis S.R., Ohio D., Rowley G.: Splenic injury as a rare complication of colonoscopy. Emerg. Med. J., 147, 26(2), 2009.

11. Mackowiak P.A.: Concepts of fever. Arch. Intern. Med., 1870-81, 28, 158(17), 1998.

12. Maliyil J., Caire W., Nair R.: Splenic abscess and multiple brain abscess caused by Streptococcus intermedius in a young healthy man. Proc(Bayl Univ Med Cent).,195-9, 24(3), 2011. 